\title{
Towards an Ecological Perspective on Learning and the Stories People Tell
}

\author{
Alan Bainbridge, Laura Formenti and Linden West
}

ESREA's Life History and Biography Network has a long, compelling story to tell. Telling that story in the light of our chosen book title, is important for engaging with the various chapters. Our Network's conferences began in 1993, bringing together a diverse group of scholars from all over Europe who were using biographical methods, albeit in varied ways, often with different assumptions about the nature and purpose of research. The idea was to share their research experiences on wide-ranging topics relating to adult education and learning in the broadest sense, informal, non-formal and formal.

The Network has been meeting for more than 25 years, with annual conferences, centred on the role of biographical narratives, auto/biography, storytelling, subjectivity and intersubjectivity, as well as memory, in researching lives and experiences of learning. Thematic, methodological and disciplinary interests alongside dissatisfaction with many traditional research methods and epistemologies - have drawn this community of researchers together, from different contexts, language communities and with varying preoccupations. The book is a testimony to the depth and variety of contributions that participants bring to discussions. Over the last few years, we have moved to considering biographical struggles to define and live sustainable lives, located within families, communities, cultures, politics and our relationships to the natural world. Our book is an attempt to illuminate what amounts to an ecology of life and human flourishing, no less, in a world that can be tortured, fractious, fragmented, fragile and yet still provide rich resources of hope.

Doing biographical research is no isolated, individual, solipsistic endeavor but is shaped by larger ecological interactions - in families, schools, universities, communities, societies and networks - that sustain or destroy hope. Sustainability is often to do with creating sufficient hope in individuals and communities by building meaningful dialogue and creating good enough experiences of togetherness, across difference. We have become more aware, in our research meetings, that telling life stories or listening to them celebrates the

(C) ALAN BAINBRIDGE, LAURAFORMENTIANDLINDENWEST, 2021 ～DOI: 10.1163/9789004465916_001 This is an open access chapter distributed under the terms of the CC BY-NC 4.0 License. 
complexity, messiness, ecological challenge but also rich potential of learning lives. But we have grown more concerned about the rapid disruption of sustainable ecologies, not only 'natural', physical, and biological, but also psychological, economic, relational, political, educational, cultural, and ethical. We live in a precarious, frightening, liquid Covid world and believe that our kind of research can both chronicle this while also illuminating how resources of hope are created in deeper, aesthetically satisfying ways. Biographical research offers insights, and even signposts, to understand and transcend the often ignored or defended darker side of the human condition, alongside its inspirations.

We note how the Life History and Biography Network is set within a changing conceptual field of adult/lifelong education and learning. Our work is framed (and constrained) by local, national, European and global influences. Particularly, the changing nature of network membership and preoccupations, in the face of neo-liberalism, including in universities and education; and of declining trust in politics, institutions, experts and the future in Europe and beyond. Rightist populism and fascism are on the march once again. So, our reflections on the evolution of our community, and our dilemmas as researchers and adult learners, in present times, point to a considered and determinedly positive interplay with these wider forces. This is part of the book's rationale: to generate insight into people's fears and anxieties but also their capacity to keep on keeping on and to challenge forces that would diminish our humanity. We, as researchers, teachers and citizens, are embedded in a liquid, runaway, fractious, anxiety ridden world but have responsibilities to struggle towards something better, grounded in social justice.

Nicoll and Biesta's (2014) '(His)story of EsREA' report highlighted the difficult relationship between research, policy, and practice within many ESREA networks. There has been much questioning, and different positions articulated, in relation to how research should be defined and orientated, and the role of academic research in relation to policy and practice. There is no one agreed answer to the question of how - and if - academic activities such as conferences and publications (should) contribute to the 'field' of policy and practice. Such relationships and debates are part of what we refer to as researching and illuminating 'the ecology of living and learning'. This is different from the early years of the Network when the main concern was to establish and validate life history and biographical methods, either to illuminate the dialectic of subjectivity and social structures, or their role in the training of educators. While important questions remain, for instance about doing biographical narrative interviews, the bigger issue is how these methods can offer meaningful feedback on different adult education practice and theorising, encompassing the political, economic, intersubjective as well as ideological worlds in which 
learning lives are located. Maybe, as a result, helping transform practice and theory in the struggle for better, more sustainable learning and living ecologies.

In different ways, many members of the Life History and Biography Network already strive to "make a difference" (Formenti \& West, 2016) in their varying contexts, via evolving practices of narrative and auto/biographical research. New methodological and epistemological debates have emerged around arts-based, performative, as well as interpretative inquiry. This includes the researcher's experience as a site for research, in struggles to create resources of hope (autoethnography, auto/biography, duoethnography, etc.). Narrative methods have proved themselves to be highly appropriate and richly generative in illuminating the complexity of life, and its enhancement, in inclusive ways. This has been done by providing "stories" (often beyond words, or the "classical" interview) with rich contextualized interpretation, illuminating not only how adults learn to live within their personal, cultural and professional worlds, in subjective and private ways, but how they can create new social and political knowledge to build more inclusive communities. How people can be empowered to find voice, to talk back to power, and create new resources of hope in struggles for sustainable lifeworlds is a, if not the central preoccupation across the chapters.

Our worlds are complex. Stories can sustain our understanding of the individual (micro) level, and of relationships in families, workplaces, communities, organizations (the meso level); and of the big processes of change in history, in the larger society, and even the whole planet (macro level). We include the virtual world. So, living' may be understood within complex interactions with others, and otherness, and with diverse processes, systems and encounters with the physical as well as virtual world. This is the complexity of life and living that the Life History and Biography Network seeks to investigate, which raises a question in turn about the ecological vitality of the network itself. How much, in other words, does the Network enliven and enrich the educational, social, political and ecological imaginations of those who participate?

There was a need, at first, in the Network, to establish or reinvigorate research on adult education because it remained a marginalized field in the academy. If biographical methods were beginning to gain more attention across the social sciences, and within adult education and in studies of professional lives, including teachers, then its standing was never strong (Merrill \& West, 2009). There was also the desire, among this 'family' of researchers, post the fall of 
the Berlin Wall, to contribute to building a better, more inclusive Europe, by bringing scholars and research students together, from East and West, North and South, as a contribution to the bigger project.

Beside such shared zeal, there was always and inevitably tension. The question of what was an acceptable definition, or even a scientific standard, for "biographical" or "life history" methodologies was frequently raised. Some researchers were focused on illuminating and developing educational practice and valued the relationship between research and intervention, interviewer and interviewee, while others positioned themselves as "pure researchers" seeking to gain greater recognition and credibility within academic disciplines and institutions. A number of researchers came from the colder lands of Northern Europe, bringing, maybe, more of an objectivist imperative, alongside standardized empirical practice, and strong interpretative procedures. Others, from the sunnier shores of the Mediterranean, had different backgrounds and a penchant for an applied philosophy; for less standardization and for a relational creativity (and sometimes messiness) in doing research. In the Western archipelago of Europe, researchers were attracted by the apparent rigor of German biographical approaches in sociology, but there were others who preferred the more relational emphasis of feminist methodologies. There was a kind of tension between methodological and epistemological coherence and celebrations of diversity. Any attempt to determine a common methodology or disciplinary framing, in some perspectives, risked being anti-experimental and even anti-ecological. It was best to celebrate various research forms and practices if they could bring new life, insight, epistemological sophistication as well as aesthetic satisfaction. Like the American pragmatists, what mattered was the search for the good and beautiful, and what enhanced life and learning.

The 2018 LHBN conference theme 'togetherness and its discontents' provided a space to explore such tensions, with its echoes of Freud's (1930) Civilisation and its Discontents. Freud emphasized a living contradiction between what we might call personal instinctual desires, and a sort of social necessity, in which individuals needed to adjust to social realities, and often repress various desires - sexual or aggressive - in the interests of social harmony and their own well-being. We wonder if there is a parallel in the urge for greater consistency in research design, compared to the more eclectic, experimental, and idiosyncratic in research. Where id is, ego shall be; maybe. Whatever the reason, the Network has struggled with but also benefited from various discontents and vigorous debate: over purpose (a more practical or academic orientation), objectivity and subjectivity, (minimizing or enhancing the researcher's presence, for instance), and or attaining rigorous respectability in the academy, as against enabling a thousand flowers to bloom. 
There were Network conferences where dissent was particularly marked. At a Triennial Conference of all ESREA Networks, there was fracture in the leadership of the Network. There were issues, as suggested, to do with the intellectual and methodological inclusivity of our work, with especial reference to Southern European traditions. At one Conference there was a major debate about the scientific quality of our conferences. Each conference in fact raised crucial issues about the Network's identity, its inclusivity, and the intellectual influences at work in engaging with the stories people tell. These issues remain alive today, in the Network and of course beyond.

The original leaders of the Network - Pierre Dominicé and Peter Alheit were progressive and collaborative in their work. They used a metaphor of 'patchworking' (West et al., 2007), and applied this to the work of 'educational biography' and the struggle for agency across lives. In Pierre's perspective, it represented a deep search for self and a quest for cultural identity and professional competence. The point was to conceive our biographies as the potential locus for meaning and authenticity, and a resource for the broader education of self as well as the capacity to work humanely with others.

Pierre Dominicé (2000) developed educational biography workshops at Geneva, in which a range of people, actual and would-be professionals, came together. They told stories in small groups, and worked over time, iteratively, to create written biographies, drawing on their own lives but also the educational resources of the group. They were offered theoretical resources like Paul Ricoeur and hermeneutics. Ricoeur wrote of writing as an act of testimony about one's own life and identity. Educational biography was not primarily a tool for better knowledge of adult development or adult psychology and did not belong either to the domain of psychology or sociology. Instead it offered insight into what it means for an adult to become more of a subject in his or her life. Doing biographies can be a process of subjectification, as against socialization, where the latter has to do with fitting people into to the established order, maybe by learning to be a good employee, or citizen. Subjectification is about learning from here and now experience, surrounding our capacity for agency, for being a person and citizen in our own right, if never in conditions of our choosing.

Peter Alheit is a sociologist, who looked back to the Chicago School and American pragmatism. He engaged with the ideas of Ulrich Beck, Pierre Bourdieu and Fritz Schütze (Alheit \& Dausien, 2007). Peter wrote of the feeling we have of being the organizers of our life course. We are planners, whether for the dream job, a political career, homebuilding or finding a good match. We even plan to lose 10 pounds in weight or give up smoking... creating the impression that we hold our own lives in our hands, that we are the authors 
of our own biography. But this is partly illusion. Fate can deal us a blow at any time, like illness, the loss of a loved one or a valued job. And our supposed autonomy of action and planning is subordinated to 'processual structures' in our biographies. We influence these only to marginal extents, as in schooling, vocational training, work, or in trajectories of unemployment, a drug career, let alone when facing unconscious desire like coming out gay, late in life.

Structure and subjectivity in interaction, and we are not as free, it was suggested, as we may sometimes imagine. But for Peter Alheit, even within such constraints, we have more opportunities than we will ever put into practice (Alheit \& Dausien, 2007). There are unlived lives within our biographies and we can become aware of the structures, or unquestioned certainties, or discourses, functioning in and constraining our lives. The habitus can be reflexively understood and our unlived lives have the potential to become socially explosive forces for change as well as of profound personal significance. This is a political as well as personal ambition of Alheit's framing of biographicity.

There were discontents in the Network, as noted. The educational emphasis clashed with the more scientific search for patterns or regularities across large samples. Or with what biographies teach us of the workings of the social order (Alheit, 1995). Especially in a world of enticement and promise, as well as illusions around the self-authorship of a life. Peter Alheit was pre-occupied with the status of biographical research in the discipline of sociology. If there was a turn, a looking back to the Chicago School and forward to the potential for biographicity, there remained many in the academy who questioned the value of personal testimony or biographical work. We need to remember German history: it is always possible to demonstrate the illusions that surround and infuse the stories people, we, tell. Hannah Arendt (1958) wrote of what happens in totalitarian societies, like the DDR, when a neighbor goes missing: no one wants to know, memory can be obliterated and highly selective stories are told.

There was rarely a tension between senior and junior researchers, or older members and newcomers, however. The narrative of the Network has always stressed inclusivity, which is not always the case with research groupings. Laura was shocked in her first meeting in 1993, as she has mentioned on many occasions: coming, as she did, from an Italian and very patriarchal academy, where a beginner PhD student was asked simply to listen and learn; here she was welcomed even though her ideas were still very sketchy and her research was still-to-be-completed on using biographical methods to sustain adult learning.

There were other tensions, reflecting no doubt different language communities, academic cultures, paradigms, and occasionally conflict and struggles for power. We struggled to attract more colleagues from the Francophone world, although many efforts were made (González-Monteagudo, 2008). A small 
number of colleagues left the Network over the question of scientific standards and the kind of conferences we held. Too much art, collage, music and movement were not to everyone's taste. Even so the Network survived and thrived, for almost three decades now. Many of us use the word "home", or "family" to express what this community means to us (Formenti \& West, 2018). How did this happen? We can say, if with varying degrees of emphasis, that our objects of study and our research methods - narrative, biographical, auto/biographical - are strongly relational, touching depth in human experience; while doing research can be transformative for both researchers and the subjects of enquiry alike. So, we learned - as coordinators - to manage the struggles, conflicts and self/other relationship demands. But this is not the whole explanation. Educators are not simply "good people". Researchers are not either. Togetherness is always a challenge. Creating and maintaining a community, as a learning space for adults, requires perpetual effort of taking care of complexity in a collaborative, responsible and developmental way. The complexity of the process must and has been acknowledged: of different needs, of the play of emotions and different expectations, and recognition of external pressures on the group. Discontents and centrifugal forces are always and inevitably there, alongside the urge for community, dialogue, respect for difference and the desire to learn from each other.

The pioneers of adult education knew some of the above rather well: the workers tutorial class movement in the UK, the adult education circles in Italy, the feminist groups working towards self-consciousness, community adult educators all over the world, know this too but also how difficult, tricky, messy, and fragile human togetherness is. When Linden became the Convenor of the Network, followed by Laura and more recently Alan, he brought an awareness that the quality of the space - physical, symbolic, and relational - of conferences mattered greatly. We know many conferences where people participate for the sake of their presentations alone. They do not particularly listen to each other, let alone learn from the experience of the conference itself. There are clear hierarchies in the structuring of sessions. This is deeply unsatisfactory, especially for people who work in education. It represents a kind of dismissal of the very nature of learning and research. Research is in fact a form of learning, in its own right, while creating a community involves maximizing the potentiality of learning from experience, from otherness, as well as self. What do we learn from our participation in the academic system? What kind of people are we and do we become? Which values should we celebrate and why, are constant questions in the Network's life.

So, we have tried to enable the LHBN Network to become a vibrant community, critically engaged in a reflexively collective as well as individual process. 
A community serving as a good enough ecology of learning and life, to help researchers develop their ideas and identities. There can be, from time to time, a strong feeling of connectivity, of good practice and conceptual sophistication to inspire and make a difference to research in the troubled world "out there". The evidence is to be found in the following, diverse chapters.

Empowering researchers is a prime task for this community: the goal is to encourage the development of meaning-full research in the struggle for a better society, as in ESREA's overall rationale. It is not simply achieving excellent results in research (as our institutions constantly insist, we must, but occasionally in ways that are destructive to lives, well-being and the quality of research itself). Remembering, too, that the Network was forged out of a desire to contribute to building a better Europe, and to heal the centuries old wounds between the Francophone and German speaking world as well as to transcend the demons of destruction haunting the European imagination. Pierre Dominicé, from Romandie, represented the French speaking world, and Peter Alheit, the German. We are living in times where Europe is once again fragile and fractured and the old demons of nationalism, racism and xenophobia rear their heads.

Struggling for social justice has been another goal for the Network. We are a microcosm of the whole and try to create good enough learning, dialogical and just spaces across our differences. Understanding intimate relational processes has also been a preoccupation. Alan and Linden are psychoanalytic psychotherapists while Laura trained in the Milano School of systemic therapy. What happens intersubjectively between people, and in their inner worlds, and how this can be theorized has mattered, alongside, or maybe as part of the struggle for social justice and a fairer share of the planet's resources. Some people emphasize the socio-cultural, others the intersubjective and psychic, but these differing dimensions all matter, in learning from each other. Too often the sociological is separated from the psychological, and academic disciplines act like warring tribes. We can often only seek reinforcement of our existing perspectives, to the neglect of others. Maybe because our Network's focus is on people, in context, and the difficulties, even mystery of not understanding why they may act as they do, we understand that collaboration is essential. But such qualities have not always been evident, and it has been a struggle to practice what we preach. We have engaged with complex political and personal questions about research and adult education in struggles for a better world. We have explored how narratives are deeply embodied (not simply formed in the mind); and how people and their stories are embedded in cultures and ecologies of precarious life (the topic of a conference in Odense, 2013; see Formenti, West, \& Horsdal, 2014). We moved explicitly to questions of the politics of biographical narrative research, in Magdeburg, 2014, in a divided, 
increasingly unequal and troubled continent (Evans, 2016). And we considered the transforming potential of stories in Milano, 2015 (Formenti \& West, 2016); and in Canterbury, in 2016, where resources of hope might lie in research and contemporary adult education. In 2017, in Copenhagen, we critically engaged with the theme of the discourses we live by, including the ecological, and asked whether our lives enhance or help destroy, and if our meso worlds are really open to diversity (Wright \& Høyen, 2020). Across all this work, arts-based methods have been more confidently woven into the repertoire. We continue to search for the 'good' and beautiful in adult education, in our research and wider lives and action, recognizing, always, that what we do is a perpetual experiment in creating more satisfying social forms.

We are aware of the relative absence of colleagues from particular countries in this collection, and that our evolution does not appeal to everyone. The German speaking world and Eastern Europe are under-represented. It is worth recalling that the Network's first book, published in 1995, in Vienna, by Verband Weiner Volksbildung, had various German speaking contributors, but a number of these researchers were never involved again. What to do about under-representation from certain countries is a constant question, as are concerns about the Network's life future. Adult or popular collective education, of a questioning and critical kind - a tradition from which many of us come and to which our biographical work often relates - has been perpetually marginalized, over decades: at the same time as forces in Europe that have little or nothing to do with civility, democracy or conviviality have strengthened. 'There are populist currents with dangerously fascistic tendencies', wrote Peter Alheit, Pierre Dominicé, Agnieszka Bron and Elisabeth Brugger in their introduction to the 1995 book. The political turn in some of our recent conferences suggests disturbing trends have worsened, and the need for subtler understanding of why, and how they can be resisted, has strengthened.

We should mention, again, that any turn to biographical and narrative research can count for little among policy makers in some parts of the world; or it continues to be treated sceptically by many academic colleagues. Strange, really, given its power to illuminate how people's hearts and minds are often colonized by demeaning discourses of racism, gender or fundamentalism, but that the means can be found for resistance, sometimes in surprising places like a sewing class, or women's health group (West, 2016). Our work chronicles and illuminates the dystopic, destructive as well as generous, inclusive, learning possibilities in lives, across Europe and beyond.

The idea of this book was born in 2018. We were meeting in Turin, during a snowstorm in the city. There were old and new people sharing their research, thoughts and experiences on togetherness, connectivity, belonging, cooperation, conflict, and separation. The Network felt "like home" again. We 
used our intelligence as researchers, educators, and humans, to consider the joys of togetherness, but in no simplistic Pollyanerish way. This book brings to life what was then done, and embodies the writing of diverse colleagues, in their struggles for togetherness as researchers, in classes, and diverse groups; to create, in other words, vibrant ecologies of life and learning. There was in fact a powerful and poignant reminder of darkness in the Research Foundation in Turin where we working at this time. It was the location for a violent attack by the Red Brigades, which had emerged in Italy in the 1970s, in the name of liberation and hatred of bourgeois democracy. People were murdered in this place. We were reminded of what can happen when dialogue breaks down and hate captures hearts and minds. Some take it upon themselves to lead the people, cavorting with a Kalashnikov or grenade. Our work and Network are grounded in a vastly different ideals: of practicing and illuminating adult education for social justice and peace, and as the means to learn our way to more sustainable, inclusive futures.

And so, these stories of a network's struggles and successes have been brought together, to think about ecologies of learning, research and conviviality. The book is divided into three overlapping parts, on Discourse, Dialogue and Difference: these three broad themes have emerged from our recent conferences. They provide a context for all the chapters, offering a contribution to evolving theoretical assumptions, methodological nuance as well as fulfilling the Network's aspirations. The part on Discourse represents the philosophical, theoretical and thematic perspectives that inform our work on stories, and a whole panoply of methodological stances.

\section{3 \\ Discourse}

In Chapter 1 Laura Formenti and Linden West consider the link between ecological and psychological crises. They reflect on a dominant epistemology, which has narrowed to very linear, narcissistic and reductive assumptions about the good. Unbridled consumerism has increased individualism, exploitation of the poor, and the narrowing of education to economic instrumentalism. It serves the needs of capitalism, rather than encouraging citizens to learn, recognize and cope with actual and impending ecological, democratic and cultural catastrophe.

Neo-liberalism, it is argued, fuels an 'ecology of bad ideas', and our world, as researchers, is not exempt from this. Critically challenging ideas are marginalized by functionalism and marketization. Objectification and obsessive quantification make it impossible to recognize the wholeness of phenomena, or of experience. Drawing on a dialogue around the ideas of 
Gregory Bateson and psychoanalysis, they illuminate how psychological problems are often interlinked with wider ecological ones: when Lake Erie is polluted, so too are our psyches. And we may not want to know about the damage we do.

In Chapter 3, Evans combines the work of Alheit, Löw and Schiffrin to investigate how past experiences are used to provide meaning in the present and even to consider future actions. Evans' research focuses on the close analysis of the micro context of an interview interaction, from which the meso and macro of experience emerge. Drawing on Alheit's theory of biographicity, here is a biographical self that can only, to a limited extent, consciously shape decisionmaking. Guided by Löw's (2001) notion of synthesis and Schiffrin's (1996) focus on verbalization, voices from the near and far are embedded in biographical (self) knowledge that although not necessarily known to the narrator, can be identified. Such work shows how lives shaped by macro forces can be found in the minutia of micro contexts. Evans uses the narrative of a Polish teacher to indicate how the complexity of time, space and culture dovetail, to make more sense of a situated learning ecology.

The reporting of experience changes over time and what was once immediate sensory awareness becomes distant memory, but this can be brought back to life through narration. Hervé Breton's chapter explores a paradox between immediacy and memory by examining two "narrative regimes": the first uses words as a descriptive phenomenology of lived experience. The second focuses on hermeneutical attempts to understand the wider ecological, social and historical dimensions of lives. Within the context and comparison of microphenomenology and biographical narrative - focused on the same event in a coffee shop in New York - Breton highlights the oscillation between phenomenological description and biographical narrative elaboration. This is then used to illuminate the construction and understanding of lifelong learning processes. A distinction is made between embodied experience, lived before it is thought about and described; and subsequent recall where such moments are re-cast within complex social and cultural worlds. The micro-phenomenological is shown to expose the 'strata' of singular experience as embedded in ecological and socio-historical worlds.

Any study of the ecology of life should include the consideration of end of life moments. How death and dying are approached and what can be learnt from them. Death has moved from being an everyday aspect of lived lives to being separate and managed within large institutional structures. Moen's chapter focuses on professionals who care for those at the end of their lives, paying attention to how past personal experiences influence professional judgments. It is noted how heavily defended individuals - patients and professionals can be when faced with the inevitability of death. The troubling subject of 
death is dealt with by either avoidance or fantasy. Moen uses the Biographical Narrative Interpretive Methodology to provide participants with opportunities to reconnect aspects of their own stories, about life and death, that due to defensiveness, may have been lost. The role of the end-of-life-professional is presented as inhabiting the meso level, having the potential to humanize and reconnect individual (micro) experience of dying and death, to the demands of organizations (neso/macro).

Wright and Høyen engage in an ambitious project to explore the ecological dynamics of a specific LHBN conference. By drawing on experience over many years, initially as novice delegates, through to conference organizers and book editors, they consider the external and internal motivators and inhibitors of the life of a conference. Beginning with Bronfenbrenner's four-level model, representing everything from the micro to the macro, Wright and Høyen seek to describe the lived-experience of delegates at a particular Life History and Biography conference. They ultimately struggled with the Bronfenbrenner model. While finding it theoretically interesting it failed, in the context of neoliberal policy, to represent the fluid interconnectivity between delegates' professional and personal lives alongside the demands of their institutions. Their thinking is transformed by a realization that the conference reflects a coming together of disparate elements, including the interrelation of people, places, papers, plenaries and social events. Of note is the under-representation of mid-career academics and the problem of how to involve and engage more such people in the activities of the network.

The next three chapters are concerned with dialogue's possibilities and preconditions in struggles to create good ecologies of life, learning and democratic social forms. In Chapter 8, Richard Sawyer argues, in the face of ecological disaster, that research claiming to be neutral and value free no longer suffices. He dialogues with researchers who interrogate different spaces within a College of Education, part of a bigger university. Richard raises questions about life histories and their intertwined relationship to diverse ecological contexts in the university. He and colleagues seek to elaborate what a more inclusive ecology of person and place might look like by walking the campus. The College can be a place of exclusion, which can also be subverted. We can shape our own spaces via forms of symbolic welcoming, in which, among other things, black and indigenous lives are made to matter. What is invisible becomes visible while inclusive symbolism is made concrete, aesthetically, 
via a picture, poem, artefact or poster etc. The chapter draws energy from several academic fields, including environmental and place-based education, curriculum theory, popular culture and life history research. The challenging dialogue engenders a transformative pedagogy of hope and resistance.

In Chapter 9, Laura Mazzoli Smith takes us into the possibility of dialogue between different epistemologies, often considered incompatible in the world of health care. Between the medical model and narrative understandings, for instance. She suggests that to know what patients endure, in illness, requires doctors to enter the imaginative worlds of patients and to see and interpret these worlds from the patients' point of view, rather than regarding them as an irritant or step towards real knowledge. Narrative knowledge offers a rich, resonant grasp of another's situation and frames of meaning, as these unfold in time. But scientific knowledge of a narrow kind can hold sway. Unlike scientific or epidemiological knowledge, which seeks to discover things about the natural world that are universally true, or appear true, narrative knowledge enables one individual to understand particular events, not as an instance of something universally true but as meaningful in its own right. However, negotiating different regimes of truth in health care is difficult because realist medical knowledge often devalues narrative ways of knowing, dismissing it as anecdote. So how to use narratives in manageable, applicable and developmental ways in health care, so as to create more substantial and eclectic ecologies of care and learning is the prime task.

Laura Mazzoli Smith turns to pragmatic philosopher Richard Rorty for a possible solution. For the pragmatist, questions of truth, or the innate essence of things, is supplanted by the question of which vocabularies and cultures can produce new and better ways of thinking and acting. In this sense, pragmatism is anti-essentialist and opposed to the idea that there is an intrinsic nature to things. Rorty maintains that we can engage with different ways of knowing without thereby losing our grip on effective standards of inquiry, or useful norms of behavior and so on. Ontological and epistemological traditions are just that - traditions. Pragmatism views science as one genre of literature, albeit a powerful one - or, put another way, literature and the arts are forms of inquiry in their own right, on the same footing as, and complementary to the scientific. Some inquiries generate propositions, some narrative insight, others evoke painting, literature and the poetic. Dialogue becomes more possible, in pragmatic perspectives, in that no one truth is absolute. Professional learners unfamiliar with narrative pedagogy, even when working with narratives, seem to find confidence in pragmatist eclecticism, if this is presented as a kind of anti-foundationalism in truth claims. It offers reassurance against stark dualism, and hence epistemic (and perhaps even ontological) threat. Dialogue 
between scientific knowledge and narrative ways of knowing, creates a better, more beautiful ecology of learning and health care.

In Chapter 10, Alan Bainbridge and Linden West focus on experiments in auto/biographical, narrative teaching and research in the context of a project called CURE, set, in part, against the backcloth of wider conflict between Israelis and Palestinians. Here dialogue most often breaks down or seems impossible. CURE was a European Union financed project to create spaces for civic education, democratic values and dialogue within teacher education in Israel. The project involves, inter alia, groups of Israeli and Palestinian educators living in Israel. But it is set against the dark historical backcloth of what remain living traumas: the Holocaust and Al Nakba (or the Catastrophe, the forced evacuation and death of many Palestinians in the 1948 War and since). Israeli Jews can continue to be haunted by the memory of the 'final solution', in the middle of the last century, as well as centuries of oppression. There can be deep and continued anxiety over security, playing out in the present. Anxiety and fear drive nationalism and colonialist oppression, religious fundamentalism, intolerance, and violence against Palestinians. Palestinians in turn can feel there is no alternative to violence, as the world turns its back on their oppression.

Trauma is thus visited onto present and future generations. It may be the failure of Israeli Jews to process deep traumatic memories that drives what is oppressively done in their name today. How much adult education, even of an intensive, in-depth therapeutic kind, might address these issues is a basic question in the chapter. Alan and Linden play with the metaphor of a key - from an old Sufi proverb about our need to search for solutions in the darkness of human experience. They have created a potential key: a playful, experimental adult education space for generating stories and a culture of listening to self, and the other. The work was palpably meaningful to many involved, but Alan and Linden struggled to transcend silence and silencing among particular Jews and Palestinians. Keys were found for some therapeutic, educational, relational, narrative, playful, even poetic dialogue: where disturbance could be managed, and people felt seen. But if the proverbial light from a candle flickered more brightly, for a moment, the darkness surrounding the conflict and in particular lives never truly receded.

Part 3 is on diversity as a constant feature of biographic enquiry. Understanding lives and learning through biographic lenses, in fact, means celebrating diversity in human experience, and across a variety of contexts and life worlds. It is about avoiding easy generalization and the blurring of difference that often 
comes with mainstream research and in its essence informed by ecological assumptions. It also means that biographical and narrative methods and perspectives are plural by definition, and able to initiate and sustain processes of nuanced diversification. So, the authors we meet in this part of the book are diverse and especially attentive to diversity in the stories they tell.

Chapter 9 is by Barbara Merrill, a pillar of our community and a critical feminist researcher, who has engaged in a lifetime's task of promoting deeper, humanistic, and subjective understanding of women's lives using biographical methods. She illuminates the interplay of class, gender, ethnic backgrounds, and structural dimensions in shaping subjective experience. But also coping strategies in Higher Education. Using feminist lenses, Barbara brings a specific contribution to the diversity of biographical methods by giving voice and richness to women's experience at university. It reveals the collective beyond the subjective, and the role of agency and structure in everyday lives, at the intersection of micro, meso and macro worlds. In fact, for more than twenty years, Barbara has chronicled experiences of working class women from different ethnic backgrounds, and their struggles and contradictions in attending courses in elite middle-class universities. But this is alongside the capacity to cope with challenging diversity in their living contexts: of family, work, university, community, and the larger society. In this chapter, she summarizes the distinctiveness of feminist theories and methodologies, and provides exemplary stories. She argues that higher education (especially in the social sciences) is a powerful experience for women. Many of the women she met, indeed, enjoyed their academic experience and became more aware of the dialectics of agency and structure, and power dynamics, shaping them and what they do. Hence, the academy can offer a transitional space enabling them to reflect upon past, present and possible futures, embracing, not rejecting their working-class identity, if in more critical ways.

In Chapter 12, we meet Fergal Finnegan and his personal commitment to criticality and critical research, as a specific approach in biographical inquiry. Fergal explores various meanings and traditions of critical research, from the Frankfurt School to Freire's pedagogy of the oppressed. In his discussion of the diversity of critical paradigms, he places some distance between what he considers the most abstract and academic exercises, and his embrace of Bhaskar's notion of "critical realism". Complexity and emergence characterize the approach: in fact, he suggests that a plurality of agents, things, events, and powers always combine in unpredictable ways. What critical biographic research can do is to grasp the ongoing interaction of structures and subjectivities within stories of self-understanding and self-monitoring. Emancipatory social science looks for explanatory depth as well as for the aims and practices of good education: human flourishing, care, solidarity, emancipation, voice, and 
resistance to dominant logics. In this framework, critical biographical research is always concerned for the larger social context and frames the biographical interview as an intersubjective encounter, where the researcher brings his/her own values, desires, position, within an institutional space. Then, the process of analysis becomes a key phase in the research process, entailing a recursive iterative movement in which the researcher brings his/her methodological, ethical and theoretical positioning. The process is far from being neutral or objective.

Biographic critical research is powerful: Fergal witnesses how it has altered his identity as a researcher and multiplied internal voices; besides, it had an impact in the field, illuminating topics of adult learning (such as the experience of non-traditional students in Higher Education), alongside better understanding of the stratifications of agency and structure. While its impact on society or the academic institution is still debatable, it seems to fuel activism as a "natural fallout".

Another crucial topic for diversity is doing biographical research with avariety of communities, whose cultural backgrounds defy the taken for granted. This is a challenge for biographical researchers, as well as an opportunity to learn and to revise our epistemological assumptions, maybe in more comprehensive and ecological directions. We should interrogate the often implicit colonialism of academic literature on "stories"; the idea of biography is itself strongly rooted in the history of Europe, in Western philosophy, epistemology, and literature. It tends to disconnect self and other, human and non-human, culture and nature. Adrienne Chan illustrates, in Chapter 11, how a researcher who has been shaped by the Anglophone academy, and worked for many years using an auto/biographic framework, is suddenly challenged and brought to reflect and to re-think her own relationship with stories. This is thanks to a land based' program of intervention within a community of First Nation People. Reading her chapter, we better appreciate the deep relationship of culture with "homeland", not as a mere background for human action, or even worse a resource to be exploited: but as a source of culture and life itself. And yet, due to the trauma of colonization and the violent separation of Indigenous people from their land, culture, language, and values, the work of healing is now necessary, and the programme invites younger generations to have renewed relationship with the land and the elderly. Storytelling seems a very reasonable way to overcome feelings of dispossession and hopelessness for many young people. So, in the programme, ancient practices of storytelling are re-actualized, allowing participants to take care of themselves in relationship with others, the elderly, the ancestors, and the environment. Indigenous epistemology praises storytelling: but the relationship with a story is different, less individualistic, connecting to traditional themes and rituals. However, an immense effort of 
understanding was needed, in a long (and still ongoing) process of what we can call co-learning, with humility, curiosity, and respect on the researcher's side. The researcher's journey within this territory and community of Stó:lō became a personal, collective, and political endeavor.

Another way to celebrate diversity, with a methodological focus, is proposed by Gaia Del Negro. She presents her PhD study of professional epistemologies of knowing and becoming, and the role of emotions, relationships, and imagination in this. She uses cooperative inquiry with two groups of adult educators in Italy (Milano Bicocca University) and the UK (Canterbury Christ Church University). She describes a participatory process of narrative aesthetic research, aimed at co-building knowledge on the research topic. This is an exploration evoking similar experiences, as in Dominicé's work in Geneva. But she does this with a stronger aesthetic and feminist thread. Once again, the researcher is actively and deeply involved in the process: her own quest for meaning and the desire for a new positioning in how we best know and are open to experience and the ecological, is shared with the participants. All of them face the potential beauty and deep challenges of their profession, and its 'irreducible uncertainty'. She invites them to explore, individually and collectively, professional experience, and the emotions it entails. She encourages stories through a panoply of approaches - narrative, metaphorical, embodied, aesthetical, and reflexive. As feminist scholars and humanistic psychotherapists have maintained, dominant Western epistemologies can alienate, as we become disconnected from who we are, as well as the other and her context. Education, here, is instead a relational process, entailing encounters with otherness, inside and outside ourselves, cultivating authenticity in how we respond. But educators 'in the patriarchal West' often learn from an overly intellectual curriculum where emotions, intuition, and creativity are marginal. There can be distance towards the other (and self). Gaia suggests 'practicing multiplicity' instead: by engaging with a variety of cultural objects, by encountering the other (the group setting is a must, in this way of working), and through 'transcoding', i.e. using different languages to tell the same story. In the process of facilitation, Gaia reflects, it became possible for her to learn how to engage with her own ambivalence, alienation, and fears.

The last chapter is about another piece of $\mathrm{PhD}$ research, and connects with the first in this part (Barbara Merrill's). In fact, Paula Stone could have been one of Barbara's participants: she uses auto-diegetic narrative to chronicle her own transformative experience - intellectual and cognitive, but also spiritual and emotional - as a student and academic in Higher Education, and then a PhD researcher. Playing the researcher and the researched, Paula analyses her path as a woman of working-class origins who learnt little by little how to recognize 
the structures of inequality acting upon her life, and her desire for recognition that was, finally, the leitmotif which allowed her to thrive in academe.

Bearing a social stigma as an 'illegitimate' daughter of an extremely poor single mother and having to carve out her own place in society, meant that nothing in her life was taken for granted. She explores the conditions that made it possible for her to find her own way and claim her space and voice in the academy. Self-narrative creates a 'third space', a 'site of exploration and struggle' where meaning can be rearticulated and self can be re-interpreted within 'broader ecological interactions, including my past, my family, and my work'. Connectedness matters, both in shaping one's life, and in reshaping it.

Yet, she writes, this is not simply one individual story; it is also collective, and any academic woman coming from a working-class background might find very similar dynamics in their own lives. In fact, Paula's story can be taken as a kind of universal narrative of inequalities, transition, and negotiation: these are common elements in the contemporary world. Where class transition, migration, life crises, environmental disasters struggle to be heard. The core issue in transition is diversity: in entering a new world, new experience, we face other frameworks of meaning, and we lack the rules of the game. Feeling like a fish out of water is a widespread human experience, in the contemporary world, far beyond class and gender. Paula suggests ways to tackle such feelings: besides telling our stories, by embracing illuminative concepts and ideas from writers who become theoretical friends, as with Axel Honneth and his concept of recognition. Love matters in dialogue and good enough relationships with supervisors. As does reciprocity in recognition, and the feeling of emotion and conflict being legitimate, alongside a capacity to imagine future possibilities.

Paula provides an appropriate end to our introduction by acknowledging our Network, as a community where she experienced 'concern, mutual respect and solidarity', allowing her to overcome the frightening feelings of vulnerability that surfaced in her first conference presentation. Intersubjectivity, rights, and solidarity are ingredients of good adult education which allow, in the longer run, for people like her to claim space, notwithstanding the careless, dismissive culture of the neo-liberal world and, at times, within it, the university.

\section{References}

Alheit, P. (1995). Taking the knocks, youth unemployment and biography - a qualitative analysis. Cassell.

Alheit, P., Bron, A., Brugger, E., \& Dominicé, P. (Eds.). (1995). The biographical approach in European adult education. Verband Wiener Volksbildung. 
Alheit, P., \& Dausien, B. (2007). Lifelong learning and biography: A competitive dynamic between the macro- and micro-level of education. In L. West, P. Alheit, B. Merrill, \& A. Siig Andersen (Eds.), Using biographical and life history methods in the study of adult and lifelong learning (pp. 57-70). Peter Lang.

Arendt, H. (1958). The human condition. University Press.

Dominicé, P. (2000). Learning from our lives; Using educational biographies with adults. Jossey-Bass.

Evans, R. (Ed.). (2016). Before, beside and after (beyond) the biographical narrative. Nisaba Verlag.

Freud, S. (2002). Civilisation and its discontents. Penguin.

Formenti, L., \& West, L. (Eds.). (2016). Stories that make a difference. Exploring the collective, social and political potential of narratives in adult education research. Pensa Multimedia.

Formenti, L., \& West, L. (2018). Transforming perspectives in lifelong learning and adult education: A dialogue. Palgrave Macmillan.

Formenti, L., West, L., \& Horsdal, M. (Eds.). (2014). Embodied narratives: Connecting stories, bodies, cultures ad ecologies. University Press of Southern Denmark.

González-Monteagudo, J. (Ed.). (2008). Approches non-francophones des histoires de vie en Europe. Pratiques de formation/Analyses, 55.

Löw, M. (2001). Raumsoziologie. Suhrkamp Verlag.

Merrill, B., \& West, L. (2009). Using biographical methods in social research. Sage.

Nicoll, K., \& Biesta, G. (2014). (His)story of the European Society of Research on the Education of Adults (ESREA): A narrative history of intellectual evolution and transformation in the field of adult education in Europe. Research report. Retrieved May 10, 2018, from https://www.esrea.org/wp-content/uploads/2016/11/ESREA_HISTORY_ REPORT_SUBMITTED.pdf

Schiffrin, D. (1996). Narrative as self-portrait: Sociolinguistic constructions of identity. Language in Society, 25(2), 167-203.

West, L. (2016). Racism, fundamentalism and a democratic education. Trentham/UCL Books.

West, L., Alheit, P., Merrill, B., \& Siig Andersen, A. (Eds.). (2007). Using biographical and life history methods in the study of adult and lifelong learning. Peter Lang.

Wright, H. R., \& Høyen, M. (2020). Discourses we live by: Narratives of educational and social endeavour. Open Book Publishers. https://www.openbookpublishers.com/ product/1110 